\title{
Smoking among women of reproductive age: how are states progressing toward the United States' year 2000 objective?
}

Paul Z Siegel, Robert K Merritt, Juliette S Kendrick, Paul D Mowery, Luis G Escobedo

\begin{abstract}
Objectives - To determine state specific trends in the prevalence of cigarette smoking among women of reproductive age (18-44 years) during 1987-1993 and to assess progress toward the year 2000 target prevalence of $\leqslant 12 \%$.

Setting and Subjects-Telephone interviews of women aged 18-44 years in the 33 states that participated in the behavioral risk factor surveillance system each year from 1987 to 1993 . The aggregate number of interviews per year ranged from 15329 to 21148 . State sample sizes ranged from 318 to 1398 each year.

Methods - Linear trend analysis of smoking prevalence among women of reproductive age in each of the 33 states, calculated using weighted least squares regression.

Results - State prevalences for smoking among women of reproductive age ranged from $15.3 \%$ to $33.7 \%$ (median = $27.1 \%$ ) in 1987 , compared with $14.7 \%$ to $32.6 \%$ (median $=23.0 \%$ ) in 1993 . A statistically significant $(p<0.05)$ decline in smoking prevalence among women of reproductive age occurred in eight of the 33 states. Most of this decline occurred during the period 1987 to 1990 ; little or no decline occurred from 1990 to 1993.

Conclusions-The decline in smoking prevalence among women of reproductive age observed in many states before 1990 appears to have levelled off. If current trends continue, few if any states are likely to achieve the year 2000 objective for smoking prevalence among women of reproductive age.
\end{abstract}

(Tobacco Control 1995; 4: 170-174)

Keywords: smoking; trend; epidemiology; prevalence; prevention; reproductive aged women

\section{Introduction}

Cigarette smoking during pregnancy increases the risk of preterm delivery, miscarriage, stillbirth, low birthweight, sudden infant death syndrome, and infant mortality. ${ }^{1}$ As well as increasing their risk of cardiovascular disease and lung cancer, women who smoke during their reproductive years also increase their risk of infertility, menstrual cycle abnormalities, and early menopause. ${ }^{2}$ Furthermore, women who smoke while using oral contraceptives increase their risk for myocardial infarction ${ }^{3}$ and stroke. ${ }^{4}$

Accordingly, the US Department of Health and Human Services has set the year 2000 target prevalence for smoking among women of reproductive age (18-44 years) at $12 \%$, three percentage points lower than the target for the general adult population. ${ }^{5}$ Despite the lower target prevalence, the smoking prevalence among women of reproductive age in 1991 was higher than the smoking prevalence among the general adult female population. ${ }^{6}$

The prevalence of smoking among reproductive aged women varies substantially among states ${ }^{7,8}$; however, there have been no published reports that compare trends among states for this demographic group. In this study we report state specific trends in the prevalence of smoking among reproductive aged women in the 33 states that participated in the behavioral risk factor surveillance system (BRFSS) each year from 1987 to 1993 . We also assess progress towards the year 2000 objective and describe geographical patterns in smoking prevalence.

\section{Methods}

DATA SOURCE

Data for the BRFSS are collected by state health departments in collaboration with the US Centers for Disease Control and Prevention (CDC). The system provides state specific information about risk factors for the leading causes of death among US adults. These risk factors include alcohol and tobacco use, obesity, lack of leisure time physical activity, and high blood pressure. ${ }^{9}$

For each year, in each participating state, an independent probability sample of households with telephones among the noninstitutionalised civilian population is selected by a multistage cluster sampling design based on the Waksberg method. ${ }^{10}$ Trained interviewers make multiple attempts to contact a household before substituting another household. After contacting a household, the interviewer randomly selects an adult 18 years of age or older for the interview. If the adult selected is not available at the time of the initial 
telephone contact, the interview is conducted during a follow up telephone call. To ensure that interviews are conducted correctly, supervisors periodically monitor all interviewers.

All states use an identical core questionnaire. The telephone interviews, which last approximately 10 to 15 minutes, are conducted on a monthly basis. This allows for the analysis of trends in health behaviours by month, quarter, or year of interview. A detailed technical description of the methods used by the BRFSS has been presented elsewhere. ${ }^{9}$

In 1987, 33 states (including the District of Columbia) participated in the BRFSS; by 1993 the number had increased to 50 . We included in the study the 33 states that participated each year from 1987 to 1993 . The data were weighted by age, race, and sex to provide estimates of health behaviours representative of the adult populations residing in each state.

PREVALENCE ESTIMATION

For this analysis, we included only women aged 18 to 44 years. The number of interviews per year among women aged 18 to 44 residing in the 33 study states increased from 15329 in 1987 to 21148 in 1993. Annual state sample sizes ranged from 318 to 1398 . We used responses to the following questions: "Have you smoked at least 100 cigarettes in your entire life?", "Do you smoke cigarettes now?", and "On average, about how many cigarettes a day do you now smoke?" A respondent who answered "yes" to the first two questions and provided an estimated number of cigarettes in response to the third was considered a current cigarette smoker. Because of the complex sample design, we used the Statistical Analysis System (SAS), version 5.18, and SESUDAAN ${ }^{11}$ to obtain prevalence estimates and standard errors for current cigarette smoking.

\section{TREND ANALYSIS}

We calculated the linear trend during the five year study period for each state, using least squares regression. We used six month intervals - producing fourteen prevalence estimates for each state - in order to maximise the number of data points ${ }^{12}$ while ensuring a minimum of 100 interviews per data point. Each prevalence estimate was weighted inversely to its variance. ${ }^{13} \mathrm{We}$ computed the slope and standard error of the slope for each linear model and determined the statistical significance of trend using a two tailed $t$ test with twelve degrees of freedom, that is, $t>$ $2.179=\mathrm{p}<0.05 .^{14}$ Box plots ${ }^{15}$ were used to visually portray trends in the distribution of state prevalences.

\section{Results}

Utah reported the lowest prevalence in each of the seven study years, whereas a variety of states reported the highest prevalences in a given year: Maine in 1987; Kentucky in 1988;
Kentucky and Rhode Island in 1989; Missouri in 1990; Tennessee in 1991; Wisconsin in 1992; and West Virginia in 1993 (table). States with the highest smoking prevalences were clustered in the midwest, whereas those with the lowest smoking prevalences were clustered west of the Mississippi river. This geographic pattern was similar in 1987 (fig 1) and 1993 (fig 2).

In 1987, the percentage of reproductive aged women who smoked cigarettes varied among states from $15.3 \%$ to $33.7 \%$ (median = $27.1 \%$ ), compared with $14.7 \%$ to $32.6 \%$ (median $=23.0 \%$ ) in 1993 (table). The annual change in smoking prevalence (slope) varied among states from -1.68 to +0.43 percentage points (median $=-0.49$ ). The middle $50 \%$ of the distribution (25th to 75 th percentile) declined steadily from 1987 to 1990 but remained essentially unchanged from 1990 to 1993 (fig 3).

A statistically significant decline $(\mathrm{p}<0.05)$ in smoking prevalence from 1987 to 1993 occurred in eight of the 33 states (table). These eight states were geographically scattered (fig $2)$. In no state was there a statistically significant increase in smoking prevalence.

\section{Discussion}

In 1993, the median state prevalence of smoking among women of reproductive age, $23.0 \%$, was nearly double the year 2000 objective ( $\leqslant 12 \%)$; in only three states was the prevalence within five percentage points of the objective. Given the lack of decline during 1990 to 1993 , few, if any, states seem likely to achieve the year 2000 objective for smoking prevalence among women of reproductive age.

Data from the $1991^{16}$ and $1992^{17}$ national health interview surveys (NHIS) also suggest a levelling off of the decline in smoking prevalence both for the total population and for women of reproductive age. This apparent levelling off has been attributed to the following two factors: (1) intensified promotional and advertising efforts by the tobacco industry, and (2) growth in the availability and market share of inexpensive cigarettes, including generic cigarettes and other discounted brands. ${ }^{16}$ It has also been suggested that as more smokers quit, an increasing percentage of the remaining smokers - the so-called "hard core" smokers" - may be less likely to quit.

The geographic pattern of states with high and low smoking prevalence among women of reproductive age - highest prevalences in the midwest and lowest prevalences west of the Mississippi river - is similar to that reported earlier. ${ }^{8}$ Similarly, smoking quit ratios have been shown to be lowest in midwestern states and highest in states west of the Mississippi river. ${ }^{19}$ Thus this pattern of geographical clustering appears to be quite stable.

Various factors may contribute to state to state variation in the prevalence of smoking among women of reproductive age. These potential determinants include age and race distribution $^{8}$; indicators of socioeconomic status such as occupation, employment status, 
Table Smoking prevalence (\%) among women aged 18-44 years, 1987-1993

\begin{tabular}{|c|c|c|c|c|c|c|c|c|c|}
\hline State & 1987 & 1988 & 1989 & 1990 & 1991 & 1992 & 1993 & Changet & $S E$ \\
\hline $\begin{array}{l}\text { Alabama } \\
\text { Arizona } \\
\text { California } \\
\text { District of } \\
\text { Columbia }\end{array}$ & $\begin{array}{l}25.6 \\
27.9 \\
20.8 \\
28.0\end{array}$ & $\begin{array}{l}25.3 \\
24.4 \\
19.7 \\
20.7\end{array}$ & $\begin{array}{l}23.2 \\
25.9 \\
20.7 \\
24.8\end{array}$ & $\begin{array}{l}22.6 \\
20.5 \\
17.2 \\
18.3\end{array}$ & $\begin{array}{l}18.1 \\
21.7 \\
17.5 \\
20.2\end{array}$ & $\begin{array}{l}20.0 \\
18.5 \\
17.0 \\
17.1\end{array}$ & $\begin{array}{l}17.0 \\
22.3 \\
18.5 \\
15.0\end{array}$ & $\begin{array}{l}-1.46^{\star} \\
-1.58^{\star} \\
-0.49^{\star} \\
-1.68^{\star}\end{array}$ & $\begin{array}{l}0.28 \\
0.54 \\
0.24 \\
0.41\end{array}$ \\
\hline Florida & 26.6 & 24.9 & 28.5 & 23.9 & 22.0 & 22.9 & 23.7 & -0.66 & 0.34 \\
\hline Georgia & 23.6 & 23.1 & 22.9 & 21.7 & 19.1 & 16.7 & 19.8 & $-1.08^{\star}$ & 0.28 \\
\hline Hawaii & 22.0 & 23.5 & 20.5 & 19.5 & 18.2 & 18.7 & 19.4 & $-0.64^{\star}$ & 0.27 \\
\hline Idaho & 23.1 & 22.2 & 20.8 & 21.5 & 21.2 & 18.1 & 22.6 & -0.40 & 0.27 \\
\hline Illinois & 27.8 & 28.5 & 26.7 & 20.0 & 27.0 & 23.1 & 23.3 & -0.74 & 0.48 \\
\hline Indiana & 30.0 & 30.5 & 29.8 & 30.0 & 27.0 & 28.6 & 29.5 & -0.32 & 0.24 \\
\hline Kentucky & 31.8 & 34.7 & 32.0 & 20.6 & 28.8 & 29.0 & 31.7 & -0.46 & 0.40 \\
\hline Maine & 33.7 & 33.7 & 30.7 & 25.7 & 28.7 & 26.3 & 26.8 & $-1.26^{\star}$ & 0.38 \\
\hline Maryland & 28.6 & 25.1 & 22.3 & 23.5 & 21.2 & 21.9 & 19.3 & $-1.11^{\star}$ & 0.31 \\
\hline Massachusetts & 29.1 & 30.9 & 26.7 & 25.0 & 26.4 & 24.6 & 24.2 & $-0.99 \star$ & 0.26 \\
\hline Minnesota & 26.7 & 25.7 & 24.0 & 25.2 & 25.9 & 24.5 & 24.9 & -0.22 & 0.31 \\
\hline Missouri & 29.3 & 30.4 & 27.0 & 33.2 & 25.8 & 26.2 & 28.6 & -0.43 & 0.52 \\
\hline Montana & 24.4 & 18.4 & 18.5 & 19.4 & 24.6 & 19.6 & 19.7 & -0.23 & 0.43 \\
\hline $\begin{array}{l}\text { New } \\
\text { Hampshire }\end{array}$ & 27.6 & 29.3 & 26.5 & 22.3 & 23.8 & 26.0 & 23.0 & -0.96 & 0.48 \\
\hline Nebraska & 27.9 & 24.2 & 24.1 & 27.0 & 24.0 & 21.3 & 28.7 & -0.07 & 0.47 \\
\hline New York & 23.9 & 27.5 & 26.8 & 26.6 & 26.5 & 24.4 & 25.0 & -0.02 & 0.75 \\
\hline New Mexico & 16.9 & 22.1 & 21.9 & 23.0 & 17.9 & 19.2 & 20.3 & +0.17 & 0.59 \\
\hline North Carolina & 23.4 & 28.5 & 26.2 & 31.3 & 21.9 & 27.9 & 28.2 & +0.43 & 0.54 \\
\hline North Dakota & 27.3 & 24.9 & 20.7 & 22.6 & 19.4 & 25.1 & 22.3 & -0.55 & 0.38 \\
\hline Ohio & 29.3 & 32.0 & 28.0 & 30.6 & 25.9 & 24.6 & 30.1 & -0.44 & 0.54 \\
\hline Rhode Island & 27.1 & 29.2 & 32.0 & 29.1 & 27.2 & 23.7 & 26.2 & -0.61 & 0.46 \\
\hline South Carolina & 21.2 & 27.4 & 22.0 & 26.1 & 25.0 & 28.1 & 22.8 & +0.38 & 0.48 \\
\hline South Dakota & 29.6 & 22.2 & 23.2 & 22.4 & 24.0 & 25.1 & 22.1 & -0.50 & 0.49 \\
\hline Tennessee & 25.4 & 28.3 & 29.8 & 28.1 & 29.7 & 27.4 & 27.6 & +0.20 & 0.34 \\
\hline Texas & 25.4 & 22.7 & 21.9 & 22.4 & 21.5 & 20.1 & 21.4 & -0.61 & 0.31 \\
\hline Utah & 15.3 & 16.2 & 17.1 & 16.0 & 14.2 & 15.0 & 14.7 & -0.26 & 0.24 \\
\hline Washington & 23.3 & 24.4 & 26.7 & 21.1 & 24.9 & 23.9 & 22.5 & -0.19 & 0.35 \\
\hline West Virginia & 29.9 & 26.8 & 29.7 & 28.4 & 28.0 & 27.1 & 32.6 & +0.30 & 0.40 \\
\hline Wisconsin & 30.5 & 32.7 & 29.8 & 26.2 & 25.0 & 30.8 & 26.2 & -0.71 & 0.39 \\
\hline Median & 27.1 & 25.3 & 25.9 & 23.0 & 24.0 & 23.9 & 23.0 & -0.49 & 0.39 \\
\hline
\end{tabular}

† Annual percentage point change, 1987-1993, based on linear regression using six month interval prevalence estimates. Annual sample sizes for states ranged from 318 to 1398 .

^Indicates statistically significant trend $(p \leqslant 0.05)$.

and family income ${ }^{8}$; differences in the intensity of cigarette advertising ${ }^{1}$ and the effectiveness of local $^{20}$ and statewide ${ }^{1,21}$ smoking control interventions; health insurance incentives, and deterrents for smokers $^{21}$; and decreasing smoking initiation and increasing smoking cessation rates among more highly educated women. ${ }^{22}$ These factors, as well as migration between states with low and high smoking prevalence, may also play a role in determining a state's rate of change in smoking prevalence.

Sociodemographic differences among states (age, race, and educational attainment) were shown not to account for state to state variation in smoking prevalence among reproductive aged women in $1989 .{ }^{\circ}$ Smoking prevalence among white and black women has been shown to be similar, ${ }^{8,23}$ further suggesting that race is not a major determinant of variation among states.

Self reported smoking status has been shown to be an accurate measure of smoking behaviour when validated by biochemical markers in several large community surveys $^{24,25}$ and in at least one large epidemiological study. ${ }^{26}$ Nevertheless, for at least three reasons smoking prevalence in the general population may be higher than that estimated by the BRFSS. First, estimates from the current population survey, in which information is collected in person (or by proxy) ${ }^{27}$ rather than by telephone, are generally about two percentage points higher than those from the BRFSS. ${ }^{1(\mathrm{p} 281)}$ Second, persons who live in households that have no telephone are more likely to smoke than are persons living in households that have a telephone. ${ }^{28}$ Third, smokers are less likely than non-smokers to respond to health surveys. ${ }^{29}$ These factors may have biased BRFSS smoking prevalence estimates downward; however, they are less likely to have affected trends.

Although data were not available for some states, those included in the study are probably reasonably representative of all states. States from all regions of the USA are included in the analysis, and the median smoking prevalence in 1991 among all 48 states that participated in

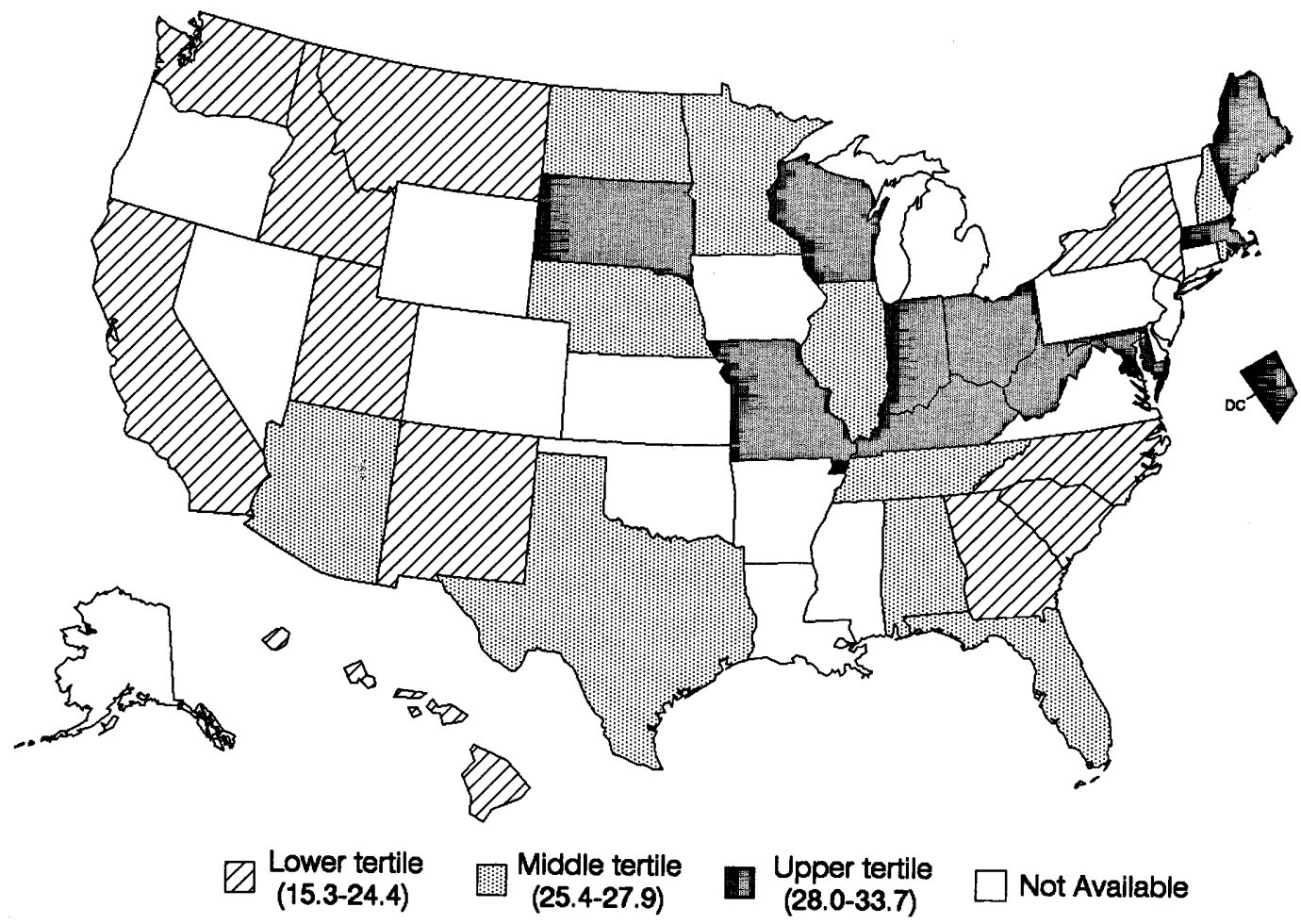

Figure 1 Smoking prevalence (\%) among women aged 18-44 years, 1987 


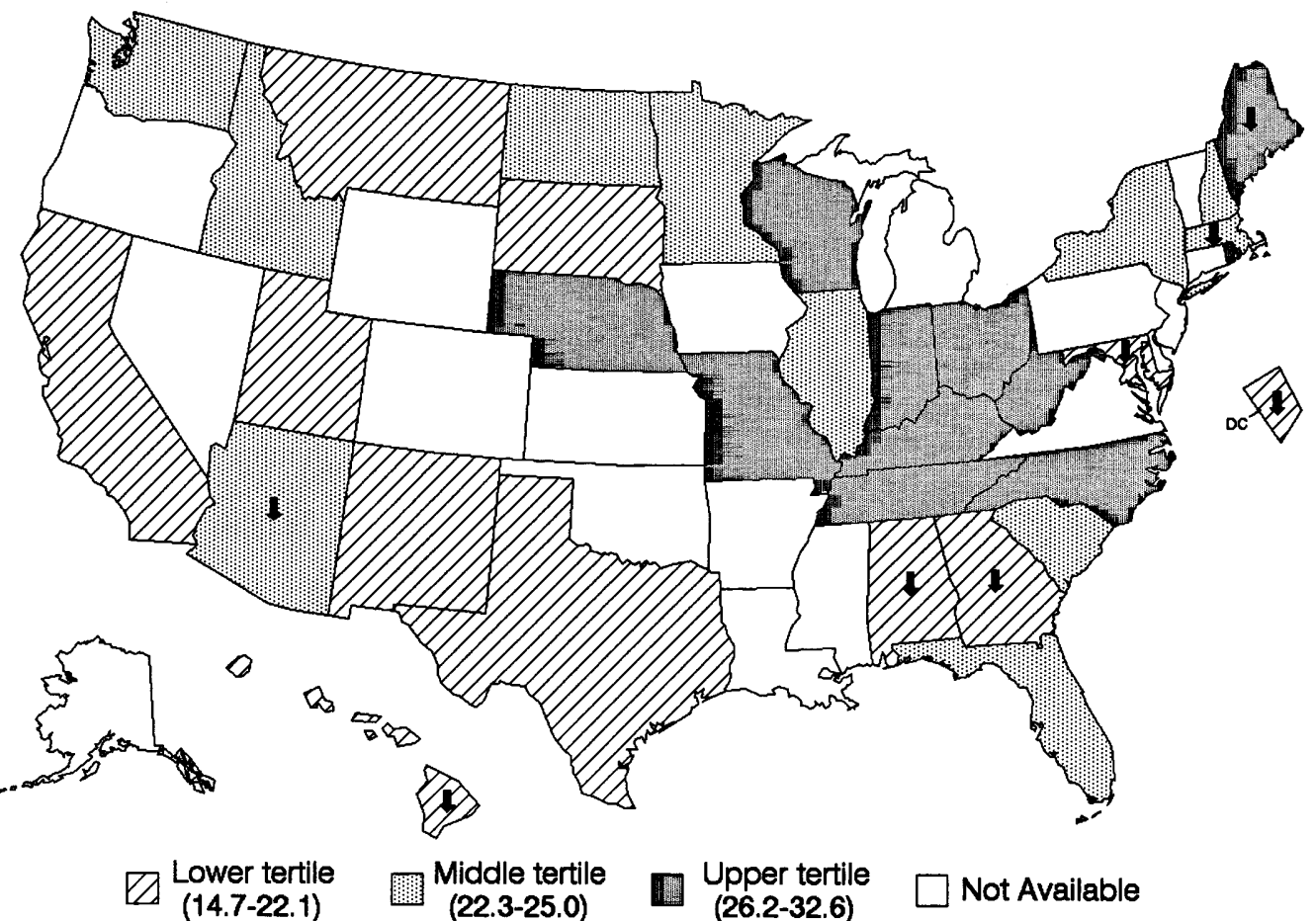

Figure 2 Smoking prevalence (\%) among women aged 18-44 years, 1993. The symbol $\downarrow$ indicates states with a statistically significant decline in prevalence during 1987-1993.

$\begin{array}{lllllll}1987 & 1988 & 1989 & 1990 & 1991 & 1992 & 1993\end{array}$

Figure 3 Box plots of the distribution of smoking prevalence (\%) among women of reproductive age for the 33 states participating in the behavioral risk factor surveillance system, 1987-1993. (Plots show maximum, minimum, median, and interquartile range.)
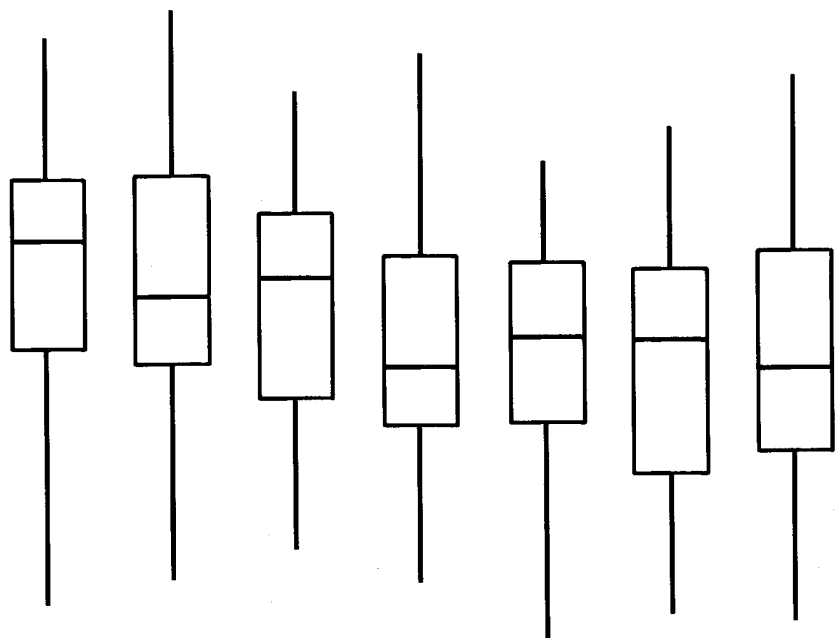

the BRFSS that year $(24.6 \%)$ is similar to the 1991 median of the 33 states included in our study $(24.0 \%)$ ?

Given the manifold adverse health effects of smoking among reproductive aged women, tobacco control measures should be pursued with particular vigour in this population subgroup. Health care providers and facilities that serve large numbers of reproductive aged women, especially those that women visit on multiple occasions, are in an excellent position to strengthen tobacco control efforts among this population. Repeated discussions are valu- able both to discourage non-smokers from starting to smoke and to help smokers to quit. ${ }^{30}$ School based, community based, and worksite tobacco control programmes have been shown to be effective, ${ }^{31}$ and several studies have shown that smoking cessation programmes for pregnant women can be cost-effective. ${ }^{32-34}$

Public health officials can use data from this study on the prevalence of and trends in smoking among women of reproductive age to assess the magnitude of this problem in their state. Further research should include efforts directed at determining which public policies, legislative approaches, and clinical practices are most effective in reducing smoking prevalence among women of reproductive age.

We thank Lanelle $R$ Henderson and Elizabeth $M$ Fitch for preparing the graphics contained in this article.

1 US Department of Health and Human Services. Reducing the health consequences of smoking : 25 years of progress. $A$ report of the Surgeon General. Rockville, Maryland Public Health Service, Centers for Disease Control, Office on Smoking and Health, 1989. (DHHS Publication No (CDC) 89-8411.)

2 Mattison DR, Thomford PJ. The effect of smoking on reproductive ability and reproductive lifespan. In : Rosenberg MJ, ed. Smoking and reproductive health. Littleton: PSG Publishing Company, 1987.

3 Shapiro S, Slone D, Rosenberg L, et al. Oral contraceptive use in relation to myocardial infarction. Lancet 1979; i: use in rela 743 .

4 Further analyses of mortality in oral contraceptive users. Lancet 1981; i: $541-6$.

5 Public Health Service. Healthy people 2000 : national health promotion and disease prevention objectives - full report with commentary. Washington, DC: US Department of Health and Human Services, 1991

6 National Center for Health Statistics. Health, United States, 1992. Hyattsville, Maryland: Public Health Service, 1993: 260.

7 Siegel PZ, Frazier EL, Mariolis P, et al. Behavioral risk factor surveillance, 1991 : monitoring progress toward the nation's year 2000 health objectives. In: CDC surveillance summaries, December 1993. MMWR 1993; 40 (No SS-4): 1-23.

8 US Centers for Disease Control. Cigarette smoking among reproductive-aged women - behavioral risk factor surveillance system, 1989. MMWR 1991; 40: 719-23. 
9 Remington PL, Smith MY, Williamson DF, Anda RF, Gentry EM, Hogelin GC. Design, characteristics, and usefulness of state-based behavioral risk factor surveilusefulness of state-based behavioral risk factor surveil-

10 Waksberg JS. Methods for random digit dialing. $f$ Am Stat Assoc 1978; 73: 40-6.

11 Shah BV. SESUDAAN: standard errors program for computing of standardized rates from sample survey data. Research Triangle Park, North Carolina: Research Triangle Institute, 1981.

12 Harrell FE, Lee KL, Matchar DB, Reichert TA. Regression models for prognostic prediction: advantages, problems, and suggested solutions. Cancer Treat Rep 1985; 69. 1071-7.

13 Neter J, Wasserman W, Kutner MH. Applied linear regression models, 2nd ed. Boston: Richard D Irwin, 1989: 419.

14 Mohr LB. Understanding significance testing. Newbury Park, CA: Sage Publications, 1990: 46

15 Williamson DF, Parker RA, Kendrick JS. The box plot: a simple visual method to interpret data. Ann Intern Med 1989

16 US Centers for Disease Control. Cigarette smoking among adults - United States, 1991. MMWR 1993; 42: 230-3.

17 US Centers for Disease Control and Prevention. Cigarette smoking among women of reproductive age-United States, 1987-1992. MMWR 1994; 43: 789-91,797.

18 Giovino GA, Shelton DM, Schooley MW. Trends in cigarette smoking cessation in the United States. Tobacco Control 1993; 2(suppl): S3-10.

19 US Centers for Disease Control. Cessation of cigarette smoking - United States, 1989. MMWR 1990; 40: 719-23.

20 National Institutes of Health. Major local tobacco control ordinances in the United States. NIH Publication No 933532, May 1993 .

21 US Centers for Disease Control and Prevention. State tobacco prevention and control activities: results of the 1989-1990 Association of State and Territorial Health Officials (ASTHO) survey final report. MMWR 1991; 40 (No RR-11): $1-40$.

22 Pierce JP, Fiore MC, Novotny TE, Hatziandreu EJ, Davis RM. Trends in cigarette smoking in the United States: educational differences are increasing. $7 A M A 1989 ; 261$. $56-60$

23 Fiore MC, Novotny TE, Pierce JP, Hatziandreu EJ, Pate KM, Davis RM. Trends in cigarette smoking in the United States: the changing influence of gender and race. FAMA 1989; 261: 49-55.

24 Pierce JP, Dwyer T, DiGiusto E, et al. Cotinine validation of self-reported smoking in commercially run community surveys. F Chron Dis 1987; 40: 689-95.

25 Wessfield JL, Holloway JJ, Kirscht JP. Effects of deceptive self-reports of quitting on the results of treatment trials for smoking: a quantitative assessment 7 Clin Epidemio $1989 ; 42: 231-43$

26 Wagenknecht LE, Burke GL, Perkins LL, Haley NJ, Friedman GD. Misclassification of smoking status in the CARDIA study: a comparison of self-report with serum cotinine levels. Am ₹ Public Health 1992; 82:33-6.

27 Marcus AC, Shopland DR, Crane LA, Lynn WR. Prevalence of cigarette smoking in the United States: estimates from the 1985 Current Population Survey. $\mathcal{F}$ Natl Cancer Inst 1989; 81: 409-14.

28 Thornberry OT, Massey JT. Trends in United States telephone coverage across time and subgroups. In Groves RM, Biemer PP, Lyberg LE, Massey JT, Nicholls WL, Waksberg I, eds. Telephone survey methodology. New York: John Wiley and Sons, 1988: 46.

29 Kleinman JC, Kopstein A. Smoking during pregnancy, 1967-1980. Am $\mathfrak{f}$ Public Health 1987; 77: 823-5.

30 Richmond R, Webster I. Evaluation of general practitioners' use of a smoking intervention programme. Int Epidemiol 1985; 14:396-401.

31 Fielding J. Smoking and women. $N$ Engl f Med 1987; 317 : 1343-5.

32 Shipp M, Croughan-Minihane MS, Petitti DB, et al. Estimation of the break-even point for smoking cessation programs in pregnancy. Am $\mathcal{F}$ Public Health 1992; 82: 383-90.

33 Lumley J. Stop smoking-again [editorial]. $B r f$ Obstet Gynaecol 1991 ; 98: 847-9.

34 Marks, JS, Koplan JP, Hogue CJ, Dalmat ME. A costbenefit/cost-effectiveness analysis of smoking cessation for pregnant women. Am F Prev Med 1990; 6: 282-9.
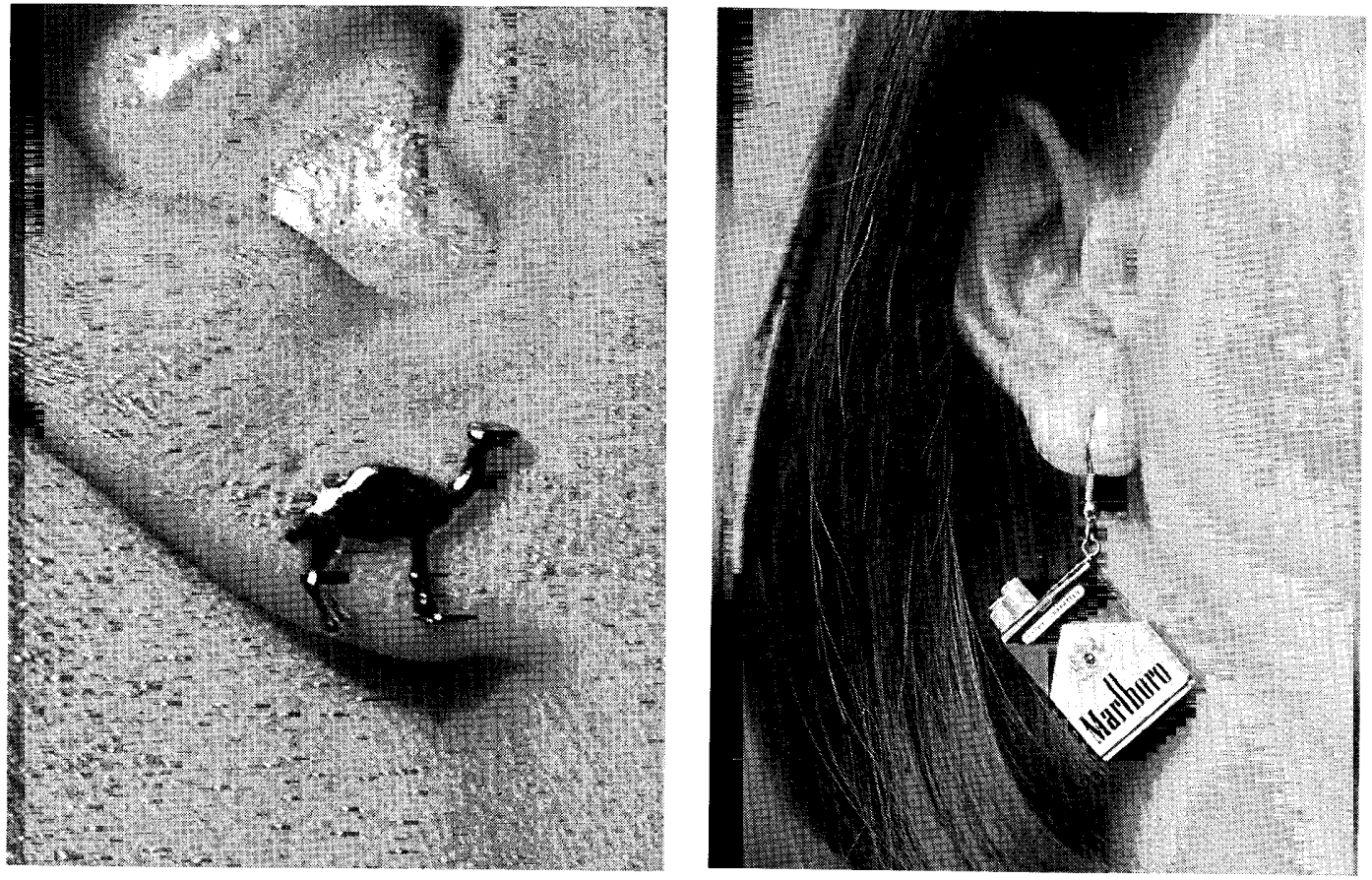

Cigarette jewellery: Camel earrings obtained for "Camel cash" coupons and Marlboro earrings from Thailand. Sources: John Slade and Prakit Vateesatokit 